\title{
Carboidratos das fibras de cotilédones e proteínas de produtos derivados de soja (Glycine max (L.) Merril)
}

\author{
Carbohydrates from cotyledon fibers and proteins of soybean (Glycine max (L.) Merril) derivatives
}

\author{
Neusa Fátima SEIBEL ${ }^{1 *}$, Adelaide Del Pino BELÉIA ${ }^{1}$
}

\begin{abstract}
Resumo
Fibras alimentares obtidas de cotilédones de soja original (FAO) e micronizada (FAM) foram fracionadas e avaliadas quanto a polissacarídeos e monossacarídeos constituintes. O componente majoritário foi a hemicelulose, totalizando 59\% em FAO e $51 \%$ na FAM, a pectina representou em média $14 \%$ e a celulose $8,5 \%$. As duas amostras de fibras apresentaram $17 \mathrm{mg} \cdot \mathrm{g}^{-1}$ de ácidos urônicos e a mesma composição de monossacarídeos, sendo galactose, glicose e arabinose/ramnose os principais componentes. As proteínas de concentrado protéico, farinha desengordurada e fibras alimentares (FAO e FAM) foram avaliadas quanto à solubilidade em diferentes solventes $(\mathrm{NaCl}$, água, etanol e $\mathrm{NaOH})$ e quanto ao peso molecular. A farinha desengordurada de soja teve a maior parte das proteínas passível de extração com solução salina, e o concentrado protéico e as fibras de cotilédones com solução alcalina. A fração protéica que não foi extraída com nenhum dos quatro solventes utilizados permaneceu no resíduo, o maior percentual estava no concentrado, seguido pela fibra alimentar micronizada e a farinha, já a menor quantidade estava na fibra alimentar original. A eletroforese das proteínas dos quatro ingredientes alimentares mostrou as subunidades que constituem as frações $\beta$-conglicinina e glicinina. Bandas com peso molecular próximo aos $30 \mathrm{kDa}$ foram reveladas nas proteínas extraídas das fibras de cotilédones de soja, sendo provavelmente glicoproteínas de parede celular, ricas em hidroxiprolina.

Palavras-chave: fracionamento de parede celular; monossacarídeos; ácidos urônicos; classificação de proteínas; eletroforese; hidroxiprolina.
\end{abstract}

\begin{abstract}
Dietary fibers from soybean cotyledons classified as original (ODF) and milled (MDF) were fractionated and evaluated as to fractions and monosaccharide composition. The major constituent was hemicellulose, 59\% in ODF and 51\% MDF, pectin was in average $14 \%$ and cellulose, $8.5 \%$. Both samples had $17 \mathrm{mg} \cdot \mathrm{g}^{-1}$ uronic acids and the same composition in monosaccharides: galactose, glucose and arabinose/rhamnose, after hydrolysis. Protein fractions extracted from protein concentrate, defatted flour and dietary fibers were evaluated for protein solubility in different solvents $(\mathrm{NaCl}$, water, ethanol and $\mathrm{NaOH})$ and for molecular weight. Defatted flour had the highest concentration of proteins soluble in saline solution, while protein concentrate and dietary fibers had the highest protein solubility in alkaline solution. Residual protein, not extracted with any of the solvents used, remained in the insoluble fraction and the highest concentration was in the protein concentrate, followed by MDF, defatted flour and ODF. Protein electrophoresis of the four food ingredients showed subunits that constitute the fractions $\beta$-conglycinin and glycinin. Protein extracted from the dietary fibers showed bands with molecular weight of about $30 \mathrm{kDa}$, probably glycoproteins from cell wall material, rich in hydroxyproline.

Keywords: cell wall fractionation; monosaccharides; uronic acids; protein classification; electrophoresis; hydroxyproline.
\end{abstract}

\section{Introdução}

A fibra de soja, ou fração insolúvel do processamento de concentrado protéico, é separada por centrifugação e contém principalmente carboidratos de parede celular dos cotilédones da soja, sem componentes da casca. É um produto que necessita de caracterização para posterior utilização. Fibras alimentares são macromoléculas resistentes à digestão pelas enzimas do trato gastrointestinal humano e são essencialmente compostas de componentes de parede celular, principalmente pectina, lignina, hemicelulose e celulose, que têm tido importância devido aos efeitos benéficos à saúde humana, como regulação do trânsito intestinal e prevenção de algumas doenças, incluindo o câncer (THARANATHAN; MAHADEVAMMA, 2003). No entanto, é necessário o conhecimento da constituição destas frações, isto é possível com o fracionamento da parede celular, que promove uma separação dos polissacarídeos, podendo então ser identificados os seus constituintes.
A pectina é rica em ramnose, arabinose, galactose e áci-

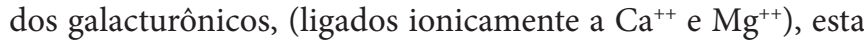
fração é covalentemente ligada a fenóis, proteínas e celulose, em todos os tipos de parede celular. Ligninas são compostos polifenólicos altamente insolúveis formados pela polimerização de três álcoois: álcool trans-p-cumaril, álcool-coniferil e álcool trans-sinapil, que mantêm uma extensa rede de ligações cruzadas na parede celular, conferindo-lhes elevada resistência, pois substituem moléculas de água entre os polímeros (BRETT; WALDRON, 1996). A hemicelulose corresponde a um grupo heterogêneo de polissacarídeos ramificados que se ligam firmemente à superfície das microfibrilas de celulose e entre si, cobrindo as microfibrilas e mantendo ligações cruzadas, via ligações de hidrogênio em uma rede complexa. A celulose é constituída exclusivamente de glicose que forma cadeias por ligações $\beta$ 1-4, e de ligações de hidrogênio entre as cadeias, com

${ }^{1}$ Departamento de Tecnologia de Alimentos, Universidade Estadual de Londrina - UEL, CP 6001, CEP 86051-970, Londrina - PR, Brasil, E-mail: neuseibel@yahoo.com.br

${ }^{*}$ A quem a correspondência deve ser enviada 
alto grau de polimerização, 2000 a 6000 na parede celular primária e mais de 10000 na parede secundária, produzindo áreas de cristalinidade (WALDRON; PARKER; SMITH, 2003).

Os polissacarídeos totais da parede celular de quatorze variedades de soja representaram em média $21 \%$ do grão, e os principais componentes foram galactose, glicose, arabinose e ácidos urônicos, enquanto que xilose, ramnose e fucose foram encontradas em menores quantidades (BRILLOUET; CARRÉ, 1983; HUISMAN; SCHOLS; VORAGEN, 1998; STOMBAUG et al., 2000).

As proteínas da soja são amplamente utilizadas em produtos alimentícios sob a forma de vários ingredientes e para este uso é importante conhecer as classes das proteínas presentes. A classificação das proteínas, usada inicialmente em cereais, é baseada na solubilização destas macromoléculas em diferentes soluções extratoras, mas alguns polipeptídeos podem ser extraídos em outra classe, devido às associações com outras proteínas ou podem permanecer no resíduo insolúvel quando associados a outros compostos (LIU, 1997). As proteínas majoritárias da soja são $\beta$-conglicinina e glicinina, respectivamente, globulinas 7 e 11S. A $\beta$-conglicinina é constituída de subunidades $\alpha, \alpha$ e $\beta$, com pesos moleculares de 84,72 e $51 \mathrm{kDa}$, respectivamente, e a glicinina tem subunidades ácidas (36-40 kDa) e básicas (18-20 kDa). Devido a diferenças na composição e estrutura, as globulinas 7 e $11 \mathrm{~S}$ exibem diferenças nas características nutricionais e funcionais (LIU, 1997; RIBLETT et al., 2001).

As proteínas de parede celular podem ser divididas em três classes estruturais. As extensinas, glicoproteínas básicas ricas em hidroxiprolina, serina, tirosina e lisina, contêm muitas seqüências repetidas de $\operatorname{Ser}(\mathrm{Hyp})_{4}$ e são os componentes majoritários da parede celular primária, podendo conter $40 \%$ de hidroxiprolina. As proteínas ricas em glicinas são caracterizadas pela repetitividade (Gly-X), em que $\mathrm{X}$ freqüentemente é glicina. As proteínas ricas em prolina e hidroxiprolina contêm unidades repetidas de Pro-Pro-Val-X-Lys, em que X freqüentemente é histidina, tirosina ou glicina (KLEIS-SAN FRANCISCO; TIERNEY, 1990; WALDRON; PARKER; SMITH, 2003). Durante o desenvolvimento do grão de soja, até $30 \%$ das extensinas podem ser extraídas por soluções salinas, no entanto, quando o grão é dessecado estas proteínas tornam-se insolúveis devido a mudanças irreversíveis da parede celular durante a secagem (CASSAB; VARNER, 1988; WALDRON; PARKER; SMITH, 2003).

Os objetivos do trabalho foram: 1) avaliar os carboidratos das fibras de cotilédones de soja, quanto aos polissacarídeos e monossacarídeos; e 2) avaliar as proteínas das fibras, da farinha desengordurada e do concentrado protéico quanto à solubilidade em diferentes solventes e à distribuição de pesos moleculares por eletroforese.

\section{Material e métodos}

As matérias-primas utilizadas para análise dos carboidratos foram fibras de cotilédones de soja original (FAO) e micronizada (FAM). Para a classificação das proteínas foram utilizados concentrado protéico, farinha desengordurada e fibras alimentares (FAO e FAM), oriundos de outro lote e com diferente composição centesimal. Todas as amostras foram fornecidas pela empresa Solae Company (Esteio/RS).

\subsection{Açúcares totais}

Foram determinados pelo método colorimétrico de fenolsulfúrico, segundo Dubois et al. (1956) e quantificados por absorção em Espectrofotômetro UV-visível Cintra 20 a 490 nm, usando uma curva de calibração de 10 pontos, com concentração de 10 a $100 \mu \mathrm{g}$ de glicose e $\mathrm{R}^{2}=0,9848$.

\section{2 Ácidos urônicos}

Foram determinados segundo Kintner e Van Buren (1982). As amostras foram hidrolisadas em ácido sulfúrico contendo tetraborato de sódio $0,0125 \mathrm{M}$, reação com m-hidroxidifenil $0,15 \%$ em $\mathrm{NaOH} 0,5 \%$, e quantificadas por absorção em Espectrofotômetro UV-visível Cintra 20 a $520 \mathrm{~nm}$. Os teores de ácidos urônicos foram calculados com base na curva de calibração de 6 pontos, com concentração de 10 a $60 \mu \mathrm{g}$ de ácido galacturônico e $\mathrm{R}^{2}=0,9791$.

\subsection{Fracionamento da parede celular}

Foi realizado a partir de $500 \mathrm{mg}$ de amostras. Primeiramente os açúcares solúveis foram extraídos com etanol $80 \%$, por 20 minutos a $80^{\circ} \mathrm{C}$, com agitação eventual. O material foi centrifugado a $8000 \mathrm{~g}$ por 15 minutos (Centrífuga Sorvall, rotor SL $50 \mathrm{~T}$ ) e o precipitado foi seco em estufa a $60^{\circ} \mathrm{C}$ por 12 horas e pesado. A extração da pectina foi conduzida com $20 \mathrm{~mL}$ de oxalato de amônio $0,5 \%(\mathrm{p} / \mathrm{v})$, para cada $200 \mathrm{mg}$ de material, este submetido à extração por 1 hora a $80^{\circ} \mathrm{C}$ com agitação constante em agitador magnético (3 vezes). Terminada a extração foi centrifugado a $8000 \mathrm{~g}$ por 15 minutos e o sobrenadante dialisado com água potável ( 4 a 5 trocas) e água destilada ( 2 a 3 trocas) e o precipitado foi lavado 3 vezes com água destilada, liofilizado e pesado. A delignificação foi realizada em banho-maria $\left(70\right.$ a $\left.80^{\circ} \mathrm{C}\right)$ com $40 \mathrm{~mL}$ de água deionizada, $1,25 \mathrm{~g}$ de clorito de sódio $(\mathrm{NaClO}), 150 \mu \mathrm{L}$ de ácido acético glacial, usando o resíduo da extração com oxalato. $\mathrm{O}$ material foi agitado manualmente para quebrar os grumos. Após 1 hora adicionou-se $0,4 \mathrm{~g}$ de $\mathrm{NaClO}$ e $150 \mu \mathrm{L}$ de ácido acético glacial. Depois de mais 1 hora de extração, o material foi centrifugado a $8000 \mathrm{~g}$ por 15 minutos, o sobrenadante foi dialisado, liofilizado e pesado, o resíduo foi lavado com água e liofilizado. As hemiceluloses foram extraídas em três frações: ao material residual foram adicionados $20 \mathrm{~mL}$ de solução $\mathrm{NaOH} 0,1 \mathrm{M}$ com $\mathrm{NaBH}_{4}\left(3 \mathrm{mg} \cdot \mathrm{mL}^{-1}\right)$, as amostras permaneceram sob agitação, com barra magnética, por 1 hora à temperatura ambiente. Em seguida, o material foi centrifugado a $8000 \mathrm{~g}$ por 15 minutos. O sobrenadante foi recolhido e neutralizado com ácido acético a pH 7,0, dialisado com água potável por 24 horas e água destilada por 24 horas e centrifugado a $8000 \mathrm{~g}$ por 15 minutos, e o sobrenadante foi liofilizado e pesado. No precipitado foi repetido o processo com adição de $\mathrm{NaOH} 1 \mathrm{M}$ mais $\mathrm{NaBH}_{4}\left(3 \mathrm{mg} \cdot \mathrm{mL}^{-1}\right)$ e depois com $\mathrm{NaOH} 4 \mathrm{M}$ mais $\mathrm{NaBH}_{4}$ (3 mg.mL $\mathrm{mL}^{-1}$ ). Metade do precipitado remanescente da extração com $\mathrm{NaOH} 4 \mathrm{M}$ foi pesado e colocado em tubos cônicos de vidro. A esse material foi adicionado reagente de Updegraff (5\% ácido nítrico e 15\% ácido acético em água) e levado ao banho-maria a 
$100{ }^{\circ} \mathrm{C}$ por 90 minutos, com agitação a cada 15 minutos. Após esfriado, foi centrifugado a 8000 g por 15 minutos a $10^{\circ} \mathrm{C}$ e o sobrenadante descartado. O precipitado foi lavado 3 vezes com água deionizada e liofilizado. $\mathrm{O}$ peso resultante da hidrólise correspondeu à fração celulósica.

\subsection{Monossacarídeos}

Foi pré-hidrolisado $1 \mathrm{mg}$ de material seco de cada fração de parede celular em $100 \mu \mathrm{L}$ de ácido sulfúrico $72 \%$, em banho-maria a $30{ }^{\circ} \mathrm{C}$, por 45 minutos. Após este período foram adicionados $1,7 \mathrm{~mL}$ de água destilada e o material foi autoclavado por 1 hora a $120^{\circ} \mathrm{C}$. Em seguida o material foi neutralizado com hidróxido de sódio $50 \%$ e submetido à retirada de sais com resinas aniônicas (Dowex 1 x 850-100 mesh, Cl Form Supelco) e catiônicas (Dowex 50w x 8 50-100 mesh, $\mathrm{H}$ Form Supelco). Os monossacarídeos foram analisados por cromatografia aniônica de alta eficiência com detector amperométrico (HPAEC-PAC) modelo DX500, em coluna CarboPac PA-1 (Dionex Corporation, Sunnyvale, CA, EUA), em corrida isocrática de $20 \mathrm{~mm}$ de $\mathrm{NaOH}$ com vazão de $1 \mathrm{~mL} /$ minuto e injeção automática de $10 \mu \mathrm{L}$. Foi utilizado padrão Sigma de monossacarídeos para comparação.

\subsection{Classificação das proteínas}

Foi realizada segundo o método modificado de Chavan, Mckenzie e Shahidi (2001). Amostras secas (2,5 g) foram dispersas em $30 \mathrm{~mL}$ de $\mathrm{NaCl} 5 \%$ e extraídas por 30 minutos em temperatura ambiente $\left(25 \pm 1^{\circ} \mathrm{C}\right)$ usando um shaker MA830/A Marconi a $125 \mathrm{rpm}$. A suspensão foi centrifugada a $4000 \mathrm{~g}$ por 20 minutos, em centrífuga Harrier 15/80 MSE, e o sobrenadante guardado. O resíduo foi reextraído uma vez, no mesmo solvente, e o sobrenadante somado ao anterior também guardado. O resíduo foi extraído sucessivamente com água deionizada, etanol $70 \%$ a $60{ }^{\circ} \mathrm{C}$ e com $\mathrm{NaOH}$ 0,2\% nas mesmas condições da extração com solução salina. As frações solubilizadas foram coletadas separadamente e determinada a proteína por Microkjeldahl. A mesma determinação foi feita no resíduo.

\subsection{Eletroforese}

Foi realizada segundo Marsman et al. (1997) e Maruyama et al. (2003). As amostras foram extraídas em solução tampão Tris-HCl 62,5 mM, pH 6,8, 2\% de SDS, $1 \%$ de $\beta$-mercaptoetanol e $10 \%$ de glicerol, durante 1 hora sob agitação com barra magnética, em seguida foram centrifugadas a $10000 \mathrm{~g}$ por 30 minutos a $10{ }^{\circ} \mathrm{C}$ em centrífuga Eppendorf modelo Centrifugue 5804R. No sobrenadante foram quantificadas as proteínas totais por Microkjeldahl. O gel de poliacrilamida (SDS-PAGE) foi usado para a análise (gel separador $12 \%$ e gel concentrador $4 \%$ ). Uma alíquota contendo $2 \mathrm{mg}$ de proteína foi diluída em tampão de amostra e utilizada para a corrida em corrente elétrica de $100 \mathrm{~V}$. As bandas eletroforéticas foram reveladas e fixadas com solução metanol $40 \%$, ácido acético $10 \%$ e água $50 \%$, contendo $0,1 \%$ de corante Coomassie Brilhante Blue. O excesso do corante foi retirado com solução metanol $40 \%$, ácido acético $10 \%$ e água $50 \%$. O padrão utilizado foi o BenchMark Protein Ladder Invitrogen, com bandas de 10 a $220 \mathrm{kDa}$.

\subsection{Hidroxiprolina}

Foi realizada segundo Woessner (1961). A hidroxiprolina foi oxidada com cloramina $\mathrm{T}$, ao complexo formado foi adicionado para-dimetilaminobenzaldeído e quantificado por absorção em Espectrofotômetro UV-visível Cintra 20 a 557 nm, usando uma curva de calibração de 9 pontos, com concentração de 0,5 a 2,5 $\mu$ g de hidroxiprolina e $\mathrm{R}^{2}=0,9958$.

\subsection{Análise estatística}

Para caracterizar as frações quanto aos monossacarídeos foi aplicada estatística Multivariada para a interpretação dos resultados, empregando-se Análise de Componentes Principais (ACP) e Análise de Agrupamentos (AA). Para isto, foram utilizados os procedimentos Multivariate Exploratory Techniques - Cluster Analysis e Principal Componentes \& Classification Analysis, do programa computacional Statistica 6.0. Os dendogramas foram obtidos por estratégia de agrupamento não ponderado aos pares e considerando-se a distância euclidiana como coeficiente de semelhança. A classificação das proteínas foi avaliada por ANOVA, e para comparar a diferença das médias foi usado o teste de Tukey com intervalo de confiança de 95\% ( $<<0,05)$.

\section{Resultados e discussão}

\subsection{Carboidratos}

As fibras de cotilédones de soja apresentaram concentrações de açúcares totais de 19,7 mg.g ${ }^{-1}$ (FAO) e 21,2 mg.g-1 (FAM), que representam os açúcares livres, enquanto que a grande maioria dos açúcares está associada formando os polissacarídeos. Além disso, muitos carboidratos solúveis foram retirados, por centrifugação, durante o processo industrial de obtenção das fibras de cotilédones. Karr-Lilienthal et al. (2005) relataram que em dez amostras de grãos de soja, os açúcares livres encontrados foram galactose, glicose e frutose, com o total variando de 0,7 a 4,7 mg.g ${ }^{-1}$.

Com o fracionamento do material de parede celular das duas amostras de fibras alimentares (Tabela 1) foi observado que o componente majoritário é a hemicelulose, totalizando $59 \%$ na amostra original e 51\% na micronizada. A extração de hemicelulose foi realizada em três etapas para ser mais eficiente. A primeira extração remove os polissacarídeos mais solúveis e promove o intumescimento das amostras. A segunda extração remove hemiceluloses de baixo grau de polimerização $(\sim 100)$, enquanto que as hemiceluloses com maior grau de polimeri-

Tabela 1. Rendimento do fracionamento da parede celular da fibra de soja (\%).

\begin{tabular}{lrr}
\hline \multicolumn{1}{c}{ Frações } & \multicolumn{1}{c}{ FAO } & \multicolumn{1}{c}{ FAM } \\
\hline Pectina & $13,2 \pm 1,3$ & $15,4 \pm 4,0$ \\
Hemicelulose (extraída em NaOH 0,1M) & $12,4 \pm 0,5$ & $13,2 \pm 0,2$ \\
Hemicelulose (extraída em NaOH 1M) & $8,1 \pm 0,7$ & $7,8 \pm 0,7$ \\
Hemicelulose (extraída em NaOH 4M) & $38,5 \pm 2,1$ & $30,1 \pm 5,2$ \\
Celulose & $8,4 \pm 1,6$ & $8,5 \pm 0,8$ \\
\hline
\end{tabular}

FAO = fibra alimentar original; FAM = fibra alimentar micronizada. Média \pm desvio padrão de análises em triplicata. 
zação ( 200) requerem uma solução de álcali mais forte, sendo retiradas na terceira extração (SELVENDRAN; O'NEILL, 1987). Ouhida, Pérez e Gasa (2002) também encontraram mais hemicelulose na fração insolúvel da farinha de soja, mas as quantidades do fracionamento foram diferentes: $40 \%$ de hemicelulose, $34 \%$ de pectina e $10,7 \%$ de celulose.

A pectina das duas amostras de fibras foi extraída com oxalato de amônio para ter a mínima degradação possível e máximo poder quelante dos cátions $\mathrm{Ca}^{++}$e $\mathrm{Mg}^{++}$, complexados com os resíduos dos ácidos galacturônicos (SELVENDRAN; O’NEILL, 1987). Esta fração rendeu 14\%, em média, estando coerente com Karr-Lilienthal et al. (2005), pois os autores comentaram que em parede celular de soja pode haver até $20 \%$ de ácidos galacturônicos. Stombaugh et al. (2000) avaliaram paredes celulares de quatorze variedades de soja encontrando, em média, 10\% de pectina, no entanto os autores definiram esta fração como a soma de galactose, arabinose, ramnose, fucose e ácidos urônicos. Os ácidos urônicos das fibras de cotilédones de soja foram quantificados nas frações pécticas e presumidamente considerados, sendo essencialmente do tipo galacturônico. As duas amostras apresentaram a mesma quantidade de $17,1 \mathrm{mg} \cdot \mathrm{g}^{-1}$, cujo valor é muito similar ao encontrado na farinha de soja (1,58\%) de uma dieta para aves, na qual era a única fonte de polissacarídeos (KARR-LILIENTHAL et al., 2005). Stombaugh et al. (2000) encontraram valores superiores, $24 \mathrm{mg} \cdot \mathrm{g}^{-1}$. Huisman, Schols e Voragen (1998) comentaram que 90\% dos ácidos urônicos presentes na farinha de soja estão na fração insolúvel, isto pode ser uma indicação da complexidade ou diversidade das moléculas pécticas na parede celular.

A celulose representou o componente minoritário da FAO e da FAM (8,5\%) porque esta fração está localizada predominantemente nas cascas de soja (STOMBAUGH et al., 2000). Ouhida, Pérez e Gasa (2002) encontraram 10,7\% de celulose nos cotilédones, mas as amostras incluíam as cascas, e comentaram que a maior parte da glicose estava na fração insolúvel das cascas. Brillouet e Carré (1983) encontraram 11\% de celulose, mas os autores usaram outro método de análise, hidrolisando a parede celular com TFA (ácido trifluoroacético) para a obtenção desta fração. A lignina teve, em média, 22\%, mas esta fração está superestimada, porque durante a delignificação, carboidratos (5-10\%), compostos fenólicos e glicoproteínas ricas em hidroxiprolina são solubilizados em clorito sódico, o reagente usado para a delignificação (SELVENDRAN; O’NEILL, 1987). Brillouet e Carré (1983) encontraram quantidades menores de lignina $(3,7 \%)$ ao analisar paredes celulares do grão de soja, porém usaram metodologias diferentes, a farinha dos grãos foi primeiramente hidrolisada com proteases e amilases e a lignina analisada por espectrofotometria.

Para uma avaliação em conjunto da capacidade de caracterização das amostras de fibras alimentares, utilizando a composição de monossacarídeos, empregou-se a Análise de Componentes Principais (ACP) e a Análise de Agrupamentos (AA). O primeiro $(\lambda \cong 4,24)$ e o segundo componente $(\lambda \cong 1,19)$ explicaram, em conjunto, $90,5 \%$ da variabilidade dos dados (Figuras 1 e 2). As Equações 1 e 2, obtidas pelos loadings ou autovalores dos CPs, geraram as coordenadas (escores) do gráfico de componentes principais (Figura 1).
CP1 $=0,922$ fucose $+0,963$ arabinose/ramnose $+0,957$ galactose 0,978 glicose $+0,768$ xilose $+0,012$ manose

$\mathrm{CP} 2=0,299$ fucose $+0,131$ arabinose/ramnose $-0,082$ galactose + 0,102 glicose $-0,277$ xilose - 0,994 manose

Com o gráfico bidimensional da ACP e o dendograma da AA (Figuras 2 e 3), foi possível verificar a distinção de dois grandes grupos: 1) fração da celulose; e 2) frações da pectina e das hemiceluloses (frações solúveis em $\mathrm{NaOH} 0,1 \mathrm{M} ; \mathrm{NaOH} 1 \mathrm{M}$ e $\mathrm{NaOH} 4 \mathrm{M}$ ). As amostras do grupo 1 ficaram isoladas das demais, pois a fração de celulose é constituída somente de glicose. No grupo 2 houve a separação das amostras da fração de $\mathrm{NaOH} 1 \mathrm{M}$,

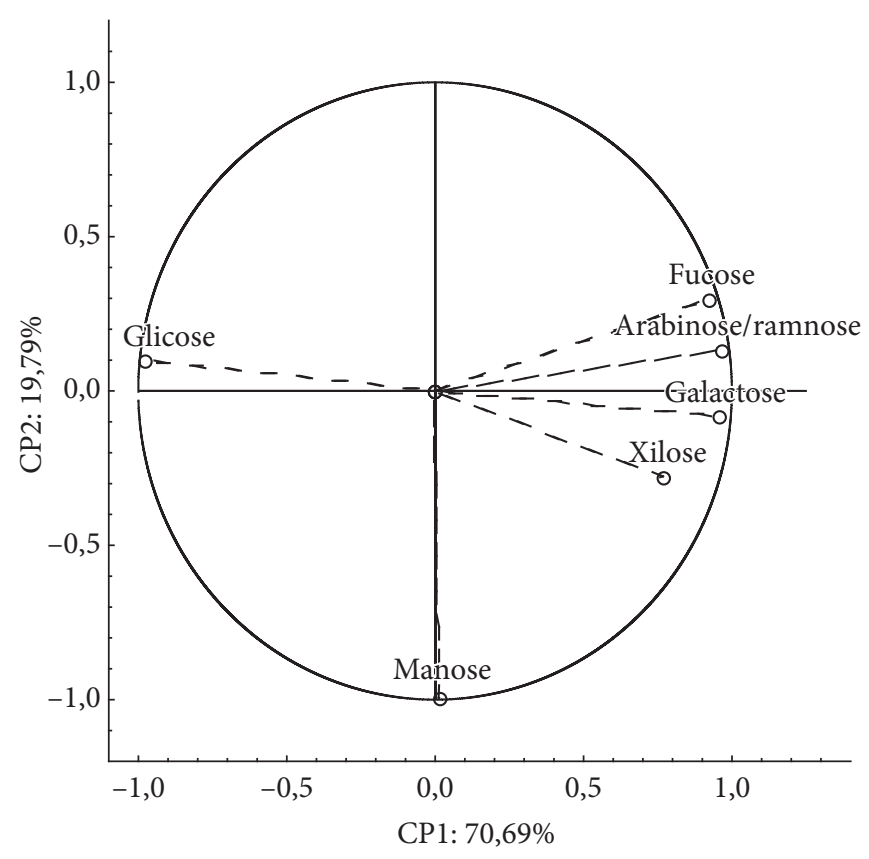

Figura 1. Projeção das variáveis nos componentes principais 1 e 2 .

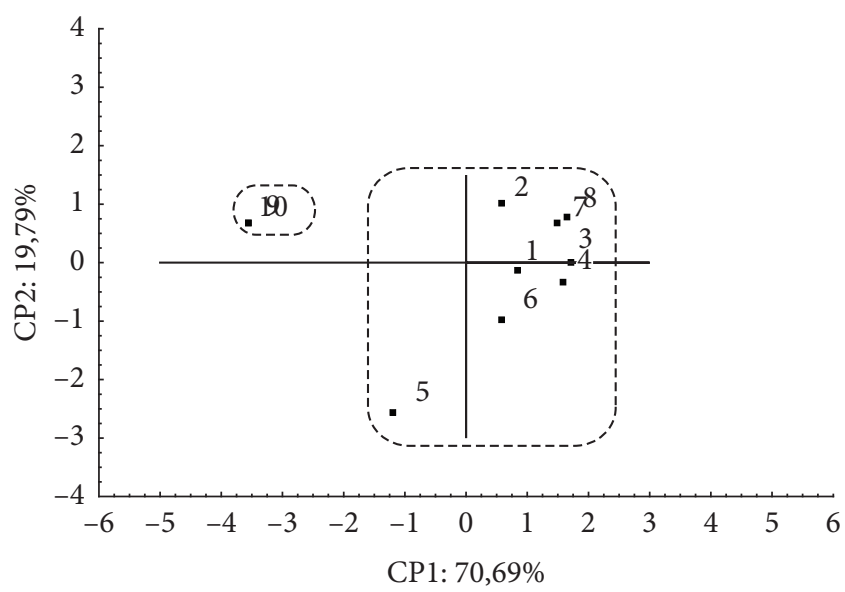

Figura 2. Análise de componentes principais obtidos a partir dos dados cromatográficos para análise de monossacarídeos. 1) FAO pectina; 2) FAM pectina; 3) FAO NaOH 0,1M; 4) FAM NaOH 0,1M; 5) FAO $\mathrm{NaOH} 1 \mathrm{M}$; 6) FAM NaOH $1 \mathrm{M}$; 7) FAO NaOH 4M; 8) FAM NaOH 4M; 9) FAO celulose; e 10) FAM celulose. 


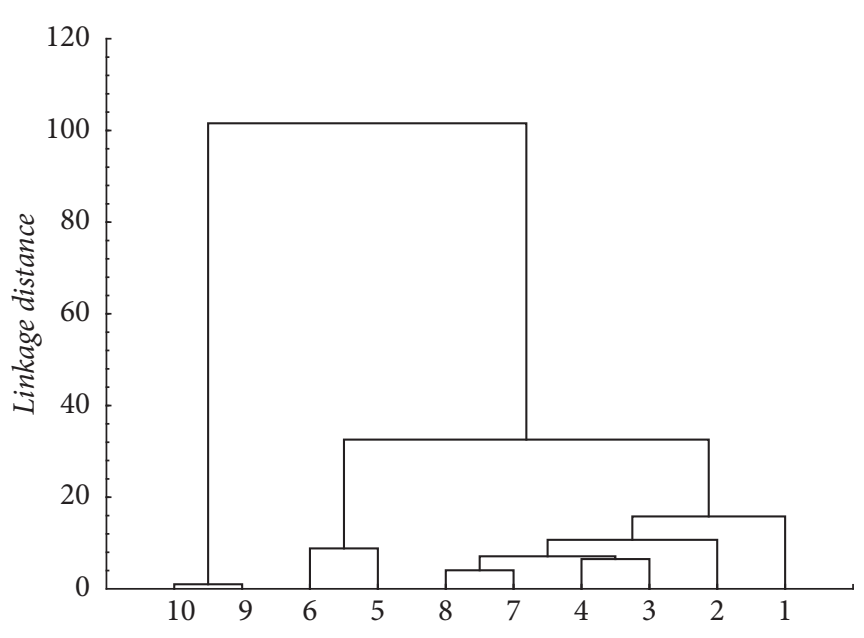

Figura 3. Dendograma da análise de agrupamento obtido a partir dos dados cromatográficos para análise de monossacarídeos. 1) FAO pectina; 2) FAM pectina; 3) FAO NaOH 0,1M; 4) FAM NaOH 0,1M; 5) FAO NaOH $1 \mathrm{M}$; 6) FAM NaOH $1 \mathrm{M}$; 7) FAO NaOH 4 M; 8) FAM $\mathrm{NaOH} 4 \mathrm{M}$; 9) FAO celulose; e 10) FAM celulose.

porque a FAO apresentou mais glicose e manose e menores níveis de arabinose/ramnose, provocando o deslocamento da amostra para baixo e para a esquerda do gráfico. As duas amostras de fibras apresentaram composição de monossacarídeos

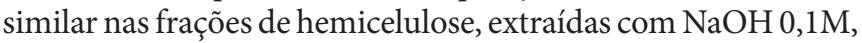
$\mathrm{NaOH} 4 \mathrm{M}$ e celulose. Na pectina, a FAO apresentou mais xilose e manose do que a FAM, por isso ficou locada mais abaixo. Estas diferenças podem ser pelo uso de diferentes variedades de soja no processamento, pois sendo as fibras provenientes de produtos industriais, não se têm conhecimento de quais variedades foram utilizadas e a amostra original pode ser de variedade diferente da micronizada. Stombaugh et al. (2003) analisando treze cultivares de soja, quanto aos monossacarídeos, encontraram diferenças nas composições devido às variedades.

Os principais monossacarídeos das fibras alimentares de soja foram galactose, glicose e arabinose/ramnose, o que está de acordo com relatos da literatura. Independentemente da metodologia utilizada, a galactose, a glicose, a arabinose e os ácidos urônicos são os principais componentes encontrados em polissacarídeos de parede celular de cotilédones de soja, enquanto que a xilose, a ramnose e a fucose são componentes encontrados em menores quantidades. Os polissacarídeos geralmente são avaliados quanto aos teores de monossacarídeos e ácidos urônicos, os quais indicam a presença das frações, ou ainda, são determinados como fibras alimentares totais, solúveis e insolúveis, para posteriormente serem hidrolisados e, então, são avaliados os monossacarídeos (BRILLOUET; CARRÉ, 1983; HUISMAN; SCHOLS; VORAGEN, 1998; MULLIN; XU, 2000; OUHIDA; PÉREZ; GASA, 2002; STOMBAUGH et al., 2000).

Os compostos de parede celular, celulose e hemicelulose são materiais higroscópicos classificados como fibras alimentares insolúveis e relacionados com as propriedades funcionais dos alimentos ricos em fibras, sendo a principal característica físico-química a propriedade de hidratação e intumescimento (LÓPEZ et al., 1996). Esta propriedade tem sido relacionada com os efeitos fisiológicos proporcionados a quem ingere a quantidade diária recomendada de fibras totais ( 25 a 30 g), sendo que $75 \%$ devem estar na forma insolúvel. Os benefícios descritos são: aumento da saciedade, regulação do trânsito intestinal, aumento do volume fecal, redução do colesterol, aumento na excreção de sais biliares e prevenção de algumas doenças, incluindo o câncer de cólon (THARANATHAN; MAHADEVAMMA, 2003).

\subsection{Proteínas}

A classificação protéica dos ingredientes alimentares derivados de soja foi realizada através da homogeneização destes em diferentes solventes para se obter as frações de proteínas extraíveis em solução salina, água, etanol, solução alcalina e fração remanescente no resíduo (Tabela 2). As quantidades de proteínas extraídas da farinha desengordurada, do concentrado protéico e das fibras de cotilédones apresentaram diferença estatística entre todas as frações solubilizadas e nas proteínas que permanecem no resíduo sólido das extrações, com exceção dos percentuais solubilizados pelo etanol na farinha e no concentrado.

A farinha desengordurada de soja tinha 69\% de proteínas, sendo a maior parte passível de extração com solução salina. $\mathrm{O}$ concentrado protéico tinha $76 \%$ de proteínas e a maior fração foi extraída em solução alcalina, assim como as proteínas das amostras de fibras de cotilédones, que inicialmente tinham $24 \%$ (original) e $43 \%$ (micronizada) de proteínas. As proteínas que constituem o resíduo devem estar associadas com outros compostos e não foram extraídas com os quatro solventes utilizados. $\mathrm{O}$ concentrado apresentou o maior percentual de proteínas não extraíveis, seguido pela fibra alimentar micronizada e a farinha, já a menor quantidade desta fração estava na fibra alimentar original.

As principais proteínas da soja são classificadas como globulinas, extraídas em solução salina, e no grão esta fração pode corresponder a até $80 \%$ do total destas macromoléculas (LIU, 1997). A farinha desengordurada, que é o primeiro produto sólido gerado no processamento da soja, teve a maior quantidade de proteínas nesta fração, pois foi a amostra com menor grau de processamento. As outras amostras podem ter sido afetadas pelo processamento subseqüente, que pode alterar as propriedades funcionais das proteínas, incluindo a solubilidade. Além disso, alguns polipeptídeos podem ser extraídos em outra classe, devido às associações com outras proteínas ou por permanecerem no resíduo insolúvel quando associados a outros compostos (LIU, 1997).

Os percentuais de proteínas extraídas das fibras de cotilédones de soja, neste trabalho, foram diferentes dos encontrados em cotilédones de beach pea (Lathyrus maritimus L.), uma leguminosa com $43 \%$ de proteínas e que contém amido (CHAVAN; McKENZIE; SHAHIDI, 2001). Os autores relataram que a maior fração de proteínas foi extraída com solução salina (62\%), seguida pela extração alcalina (19\%) e pela água (15\%), mas os autores também encontraram o menor percentual de extração em etanol (3\%). Estas variações são explicadas pelas diferenças das leguminosas e também porque os autores fizeram o processamento de separação dos cotilédones em laboratório, 
Tabela 2. Proteínas de ingredientes de soja extraídas com diferentes solventes (\% de proteínas solúveis em relação às proteínas totais).

\begin{tabular}{lccccc}
\hline \multicolumn{1}{c}{ Amostras } & Extração com NaCl & Extração com água & Extração com etanol & Extração com NaOH & Resíduo \\
\hline Farinha & $46,72^{\mathrm{a}} \pm 1,95$ & $6,26^{\mathrm{c}} \pm 0,20$ & $2,96^{\mathrm{c}} \pm 0,19$ & $18,40^{\mathrm{d}} \pm 0,24$ & $26,31^{\mathrm{b}} \pm 3,62$ \\
Concentrado & $10,26^{\mathrm{d}} \pm 0,47$ & $2,69^{\mathrm{d}} \pm 0,36$ & $1,49^{\mathrm{c}} \pm 0,19$ & $47,08^{\mathrm{a}} \pm 3,22$ & $36,96^{\mathrm{a}} \pm 3,85$ \\
FAO & $25,12^{\mathrm{b}} \pm 0,42$ & $16,78^{\mathrm{a}} \pm 1,25$ & $9,12^{\mathrm{a}} \pm 0,95$ & $30,46^{\mathrm{c}} \pm 0,06$ & $16,78^{\mathrm{c}} \pm 0,45$ \\
FAM & $17,51^{\mathrm{c}} \pm 1,08$ & $9,07^{\mathrm{b}} \pm 0,77$ & $6,08^{\mathrm{b}} \pm 0,98$ & $37,88^{\mathrm{b}} \pm 0,57$ & $26,82^{\mathrm{b}} \pm 2,38$ \\
\hline
\end{tabular}

FAO = fibra alimentar original; e FAM = fibra alimentar micronizada. Média de três extrações determinadas em duplicata \pm desvio padrão, em base seca. Médias seguidas pela mesma letra, nas colunas, não diferiram a $5 \%$ pelo teste de Tukey.

manualmente e logo após a colheita, sem os processamentos sofridos pela FAO e pela FAM.

Os quatro ingredientes alimentares derivados de soja apresentaram as proteínas majoritárias da leguminosa, a $\beta$-conglicinina e a glicinina, respectivamente, globulinas 7 e $11 \mathrm{~S}$ (Figura 4). A $\beta$-conglicinina é constituída de subunidades $\alpha, \alpha$ e $\beta$, com pesos moleculares de 84,72 e $51 \mathrm{kDa}$, respectivamente, e a glicinina tem subunidades ácidas (36 a $40 \mathrm{kDa}$ ) e básicas (18 a $20 \mathrm{kDa}$ ) (GARCIA et al., 1997; RIBLETT et al., 2001). A glicinina é a maior fração das proteínas totais do grão, 25 a 35\%, é composta por, no mínimo, seis subunidades não idênticas, totalizando um peso molecular de $350 \mathrm{kDa}$, cada subunidade tem um polipeptídeo ácido associado a um básico por ligações dissulfeto e ligações de hidrogênio (GARCIA et al., 1997; LIU, 1997; SATHE et al., 1987). Uma banda de menor intensidade foi verificada ao redor de $15 \mathrm{kDa}$, nas quatro amostras, provavelmente seria uma subunidade da glicinina, a qual também foi verificada por Riblett et al. (2001) quando avaliaram as frações 7 e 11S, separadamente, e esta fração foi revelada somente nas corridas de glicinina, com baixa intensidade. Devido a diferenças na composição e estrutura, as globulinas 7 e $11 \mathrm{~S}$ exibem diferenças nas características nutricionais e funcionais: todas as subunidades da $\beta$-conglicinina são glicoproteínas, contendo 4 a $5 \%$ de carboidratos, e somente uma pequena porção de glicinina é glicosilada; a $11 \mathrm{~S}$ tem 3 a 4 vezes mais metionina e cisteína do que a $7 \mathrm{~S}$ e melhor formação de gel, enquanto que a 7S tem melhor capacidade emulsificante (LIU, 1997).

A farinha desengordurada é o primeiro produto sólido após a retirada do óleo, portanto rico em proteínas, e o concentrado protéico é produzido com as proteínas solúveis da soja, principalmente $\beta$-conglicinina e glicinina. As fibras de cotilédones de soja são ricas em carboidratos, mas o segundo componente é a proteína (28\%). Nas fibras foi verificada uma fração remanescente de 7 e 11S, que devido aos vários processos sofridos podem ter tido a solubilidade diminuída, permanecendo na fração insolúvel. Estas proteínas podem não ter sido totalmente solubilizadas no processo de obtenção do isolado protéico, pois a solubilização ocorreu em $\mathrm{pH}$ 7-10 e a precipitação em pH 4,5, e segundo Liu (1997) o pH utilizado para a solubilização é 6,4 (11S) e 6,2 (7S) e a precipitação de 90\% da fração 11S ocorre em pH 5,5, enquanto que em $\mathrm{pH} 4,5$ a precipitação é constituída de $70 \%$ da $7 \mathrm{~S}$ e $30 \%$ da $11 \mathrm{~S}$. Devido à presença destas proteínas, as fibras de cotilédones tiveram maior solubilidade em $\mathrm{pH} 6 \mathrm{e}$ 7 , original $7,7 \%$ e micronizada $10,6 \%$, quando o efeito do $\mathrm{pH}$ na solubilidade protéica foi avaliado.

A eletroforese das proteínas das fibras também mostrou bandas com peso molecular próximo aos $30 \mathrm{kDa}$, que provavel-

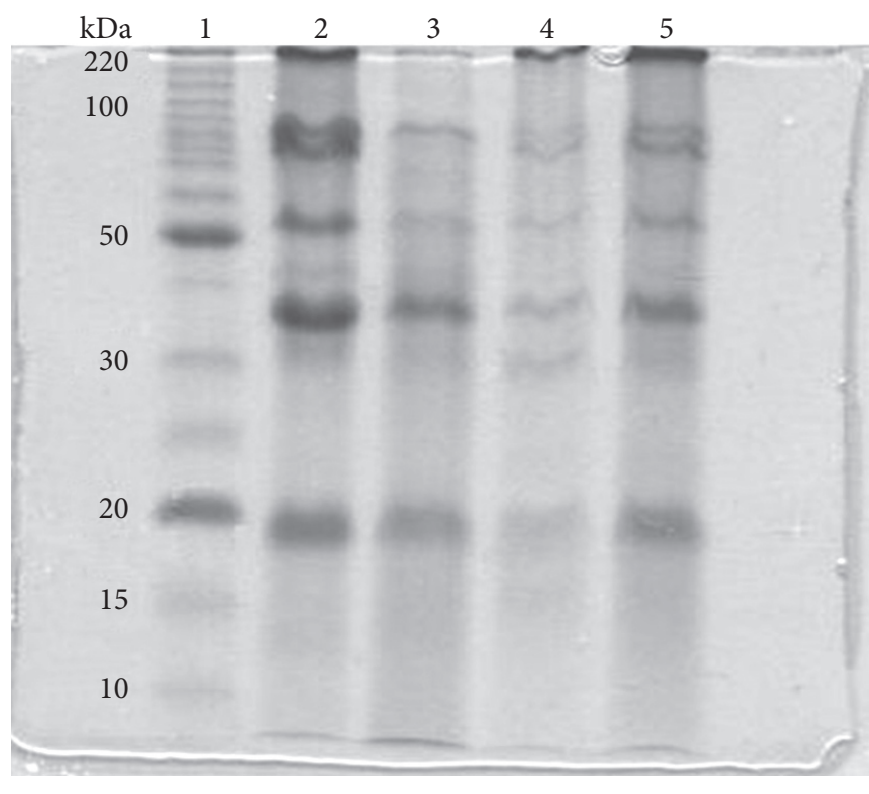

Figura 4. Eletroforese dos ingredientes alimentares derivados de soja. 1) padrão; 2) concentrado protéico; 3) farinha desengordurada; 4) fibra alimentar original; e 5) fibra alimentar micronizada.

mente são glicoproteínas de parede celular ricas em hidroxiprolina e extensinas. Segundo Kleis-San Francisco e Tierney (1990), estas proteínas têm peso molecular de 30 a $33 \mathrm{kDa}$ e têm a mesma quantidade de hidroxiprolina e prolina. Averyhart-Fullard, Datta e Marcus (1988) avaliaram proteínas de parede celular de soja ricas em hidroxiprolina pela constituição de aminoácidos, $20 \%$ destas proteínas eram hidroxiprolina e $20 \%$ eram prolina, além de aminoácidos,,estas proteínas são ricas em serina, histidina e valina. A hidroxiprolina dos ingredientes alimentares foi quantificada, as amostras de fibras de cotilédones tiveram quantidades superiores (original $381,9 \mu \mathrm{g} . \mathrm{g}^{-1}$ e micronizada $359,3 \mu \mathrm{g} \cdot \mathrm{g}^{-1}$ ) às amostras protéicas (concentrado $218,2 \mu \mathrm{g} \cdot \mathrm{g}^{-1}$ e farinha $191,5 \mu \mathrm{g} \cdot \mathrm{g}^{-1}$ ), mesmo tendo menores quantidades de proteínas, média de $28 \%$ nas fibras e $72 \%$ nos ingredientes protéicos. Estes resultados confirmam a presença de proteínas de parede celular e indicam que estas macromoléculas permanecem associadas aos outros compostos de parede celular. As extensinas são os componentes majoritários da parede celular primária, podendo conter $40 \%$ de hidroxiprolina, que está associada com arabinose na parede celular da soja. Durante o desenvolvimento do grão de soja, a maioria das extensinas (30\%) pode ser extraída por soluções salinas, no entanto, quando o grão é dessecado estas proteínas tornam-se insolúveis devido a mudanças irreversíveis na conformação da parede durante a 
secagem (CASSAB; VARNER, 1988; WALDRON; PARKER; SMITH, 2003).

\section{Conclusões}

Os dois compostos majoritários da fibra de cotilédones de soja foram caracterizados. A maior fração de carboidratos é a hemicelulose. Com a constituição dos monossacarídeos das frações houve a distinção de dois grupos: 1) celulose; e 2) pectina e hemiceluloses, sendo galactose, glicose e arabinose/ramnose os principais componentes das amostras. A maioria das proteínas da farinha desengordurada de soja foi extraída em solução salina, já a solução alcalina extraiu a maior quantidade de proteínas do concentrado protéico e das fibras de cotilédones. Na eletroforese dos quatro ingredientes alimentares derivados de soja foi constatada a presença das proteínas majoritárias $\beta$-conglicinina e glicinina, além de bandas com peso molecular próximo aos $30 \mathrm{kDa}$ nas fibras dos cotilédones, sendo provavelmente glicoproteínas de parede celular, ricas em hidroxiprolina.

\section{Agradecimentos}

Os autores agradecem ao Conselho Nacional de Pesquisa e Desenvolvimento (CNPq), pelo financiamento desta pesquisa; ao Instituto de Botânica de São Paulo, pelo uso do laboratório para a análise dos componentes de paredes celulares; à professora Marta de Toledo Benassi, pela ajuda na avaliação dos dados e à empresa Solae Company, pelo fornecimento das amostras.

\section{Referências bibliográficas}

AVERYHART-FULlARD, V.; DATTA, K.; MARCUS, A. A hydroxyproline-rich protein in the soybean cell wall. The Proceedings of the National Academy of Sciences, v. 85, n. 4, p. 1082-1085, 1988.

BRETT, C. T.; WALDRON, K. W. The molecular components o the wall. In: BRETT, C.T.; WALDRON, K. W. Physiology and Biochemistry of Plant Cell Walls. 2. ed. London: Chapman \& Hall, 1996. p. 5-43. cap. 2.

BRILlOUET, J. M.; CARRÉ, B. Composition of cell walls from cotyledons of Pisum Sativum, Vicia Faba and Glycine Max. Phytochemistry, v. 22, n. 4, p. 841-847, 1983.

CASSAB, G. I.; VARNER, J. E. Cell wall proteins. Annual Review of Plant Physiology and Plant Molecular Biology, v. 39, p. 321-353, 1988.

CHAVAN, U. D.; McKENZIE, D. B.; SHAHIDI, F. Protein classification of beach pea (Lathyrus maritimus L.). Food Chemistry, v. 75, n. 2, p. 145-153, 2001.

DUBOIS, M. et al. Colorimetric method for determination of sugars and related substances. Analytical Chemistry, v. 28, n. 3, p. 350, 1956.

GARCIA, M. C. et al. Composition and characterization of soybean and related products. Critical Reviews in Food Science and Nutrition, v. 37, n. 4, p. 361-391, 1997.

HUISMAN, M. M. H.; SCHOLS, H. A.; VORAGEN, A. G. J. Cell wall polysaccharides from soybean (Glycine max) meal. Isolation and characterization. Carbohydrate Polymers, v. 37, n. 1, p. 87-95, 1998.
KARR-LILIENTHAL, L. K. et al. Chemical and nutritional properties of soybean carbohydrates as related to nonruminants: A review. Livestock Production Science, v. 97, n. 1, p. 1-12, 2005.

KINTNER, P. K.; VAN BUREN, J. P. Carbohydrate interference and its correction in pectin analysis using the m-hydroxydiphenil method. Journal of Food Science, v. 47, n. 3, p. 756-764, 1982.

KLEIS-SAN FRANCISCO, S. M.; TIERNEY, M. L. Isolation and characterization of a proline-rich cell wall protein from soybean seedlings. Plant Physiology, v. 94, n. 4, p. 1897-1902, 1990.

LIU, K. Chemistry and Nutritional Value of Soybean Components. In: LIU, K. Soybeans: Chemistry, Technology and Utilization. New York: Chapman \& Hall, 1997. p. 25-99. cap. 2.

LÓPEZ, G. et al. Relationship between physical and hydration properties of soluble and insoluble fiber of artichoke. Journal of Agricultural and Food Chemistry, v. 44, n. 9, p. 2773-2778, 1996.

MARSMAN, G. J. P. et al. In vitro accessibility of untreated, toasted, and extruded soybean meals for proteases and carbohydrases. Journal of Agricultural and Food Chemistry, v. 45, n. 10, p. 4088-4095, 1997.

MARUYAMA, N. et al. Molecular and structural analysis of electrophoretic variants of soybean seed storage proteins. Phytochemistry, v. 64, n. 3, p. 701-708, 2003.

MULLIN, W. J.; XU, W. A study of the intervarietal differences of cotyledon and seed coat carbohydrates in soybeans. Food Research International, v. 33, n. 10, p. 883-891, 2000.

OUHIDA, I.; PÉREZ, J. F.; GASA, J. Soybean (Glycine max) cell wall composition and availability to feed enzymes. Journal of Agricultural and Food Chemistry, v. 50, n. 7, p. 1933-1938, 2002.

RIBLETT, A. L. et al. Characterization of $\beta$-conglycinin and glycinin soy protein fractions from four selected soybean genotypes. Journal of Agricultural and Food Chemistry, v. 49, n. 10, p. 4983-4989, 2001.

SATHE, S. K. et al. High-resolution sodium dodecyl sulfate polyacrylamide gel electrophoresis of soybean (Glycine max L.) seed proteins. Cereal Chemistry, v. 64, n. 6, p. 380-384, 1987.

SELVENDRAN, R. R.; O’NEILL, M. A. Isolation and analysis of cell walls from plant material. Methods of Biochemical Analysis, v. 32, p. 25-153, 1987.

STOMBAUGH, S. K. et al. Relationships between soybean seed cell wall polysaccharides, yield, and seed traits. Crop Science, v. 43, n. 2, p. 571-576, 2003.

STOMBAUGH, S. K. et al. Genotypic and environmental variation in soybean seed cell wall polysaccharides. Crop Science, v. 40, n. 2, p. 408-412, 2000.

THARANATHAN, R. N.; MAHADEVAMMA, S. Grain legumes - a boon to human nutrition. Trends in Food Science \& Technology, v. 14, n. 12, p. 507-518, 2003.

WALDRON, K. W.; PARKER, M. L.; SMITH, A. C. Plant cell walls and food quality. Comprehensive Reviews in Food Science and Food Safety, v. 2, n. 2, p. 101-119, 2003.

WOESSNER, J. F. The determination of hydroxyproline in tissue and protein samples containing small proportions of this amino acid. Archives of Biochemistry and Biophysics, v. 93, n. 2, p. 440-447, 1961. 